\title{
Anti-CD20 Depletes Meningeal B Cells but Does Not Halt the Formation of Meningeal Ectopic Lymphoid Tissue
}

Rosa Margareta Brand, Verena Friedrich, PhD, Jolien Diddens, MSc, Monika Pfaller, BSc, Francesca Romana de Franchis, MSc, Helena Radbruch, MD, Bernhard Hemmer, MD, Katja Steiger, VMD, and Klaus Lehmann-Horn, MD

Neurol Neuroimmunol Neuroinflamm 2021;8:e1012. doi:10.1212/NXI.0000000000001012

\section{Abstract}

\section{Objective}

To investigate whether anti-CD20 B-cell-depleting monoclonal antibodies (aCD20 mAbs) inhibit the formation or retention of meningeal ectopic lymphoid tissue (mELT) in a murine model of multiple sclerosis (MS).

\section{Methods}

We used a spontaneous chronic experimental autoimmune encephalomyelitis (EAE) model of mice with mutant T-cell and B-cell receptors specific for myelin oligodendrocyte glycoprotein (MOG), which develop meningeal inflammatory infiltrates resembling those described in MS. aCD20 mAbs were administered in either a preventive or a treatment regimen. The extent and cellular composition of mELT was assessed by histology and immunohistochemistry.

\section{Results}

aCD20 $\mathrm{mAb}$, applied in a paradigm to either prevent or treat EAE, did not alter the disease course in either condition. However, aCD20 mAb depleted virtually all B cells from the meningeal compartment but failed to prevent the formation of mELT altogether. Because of the absence of B cells, mELT was less densely populated with immune cells and the cellular composition was changed, with increased neutrophil granulocytes.

\section{Conclusions}

These results demonstrate that, in CNS autoimmune disease, meningeal inflammatory infiltrates may form and persist in the absence of B cells. Together with the finding that aCD20 $\mathrm{mAb}$ does not ameliorate spontaneous chronic EAE with mELT, our data suggest that mELT may have yet unknown capacities that are independent of B cells and contribute to CNS autoimmunity.
Correspondence

Dr. Lehmann-Horn

klaus.lehmann-horn@tum.de
RELATED ARTICLE

Editorial

Can Systemic Anti-CD20 B

Cell-Depleting Antibodies

Eliminate Meningeal

Follicles in Multiple

Sclerosis?

Page e1000

From the Department of Neurology (R.M.B., V.F., J.D., M.P., F.R.F., K.L.-H.), School of Medicine, Technical University of Munich; Department of Neuropathology (H.R.), Charité Universitätsmedizin Berlin; Department of Neurology (B.H.), School of Medicine, Technical University of Munich, Munich Cluster of Systems Neurology (SyNergy), Germany; and Comparative Experimental Pathology (CEP) (K.S.), Department of Pathology, School of Medicine, Technical University of Munich, Germany.

Go to Neurology.org/NN for full disclosures. Funding information is provided at the end of the article. 


\section{Glossary}

aCD20 mAb = anti-CD20 monoclonal antibody; BCR = B-cell receptor; EAE = experimental autoimmune encephalomyelitis; mELT = meningeal ectopic lymphoid tissue; $\mathbf{M O G}=$ myelin oligodendrocyte glycoprotein; MPO = myeloperoxidase; MS = multiple sclerosis; RRMS = relapsing-remitting multiple sclerosis; PMS = progressive MS; SLO = secondary lymphoid organ; LFB-PAS = Luxol fast blue and periodic acid-Schiff reaction; TCR $=$ T-cell receptor.

B-cell-depleting strategies with anti-CD20 monoclonal antibodies (aCD20 mAbs), such as rituximab, ocrelizumab, or ofatumumab, are among the most potent therapies currently available in the treatment of relapsing-remitting multiple sclerosis (RRMS). Modest efficacy has also been shown in progressive MS (PMS), specifically active primary PMS, and early, relapse-independent progression in RRMS. $^{1-4}$ Their success highlights the importance of $B$ cells for MS pathogenesis. Among other factors, the therapeutic effect of B-cell depletion may be mediated by interrupting antigen presentation by $\mathrm{B}$ cells to $\mathrm{T}$ cells in the CNS. ${ }^{5-9}$

Leukocytic infiltrates, forming meningeal ectopic lymphoid tissue (mELT), are found in patients with PMS and to a lesser extent in RRMS. They correlate with an earlier disease onset, a more rapid disease progression, and subpial cortical damage. ${ }^{10-15}$ In general, ectopic lymphoid tissue (ELT) is formed by aggregates of $\mathrm{B}$ and $\mathrm{T}$ cells, which range from tight-cell clusters to highly organized structures and resemble secondary lymphoid organs (SLOs). ${ }^{16-20}$ In a model of MS, it was demonstrated that B-cell repertoire expansion occurs in mELT, suggesting germinal center activity in the CNS. ${ }^{21}$ Hereby, mELT may facilitate smoldering autoimmunity in the CNS parenchyma sequestered beyond the blood-brain barrier. Yet, it remains unclear whether and how mELT contributes to early or progressive MS.

Because B cells are an integral part of mELT and aCD20 $\mathrm{mAb}$ that targets $\mathrm{B}$ cells not only in the periphery but also in the meninges, ${ }^{22}$ it seems possible that aCD20 $\mathrm{mAb}$ inhibits the formation or retention of mELT. Assuming that $\mathrm{mELT}$ plays a role in MS pathogenesis, preventing or suppressing mELT may contribute to the efficacy of B-cell depletion in MS. In this study, we investigated the effects of aCD20 $\mathrm{mAb}$ on mELT in a B-cell-dependent and T-cell-dependent experimental autoimmune encephalomyelitis (EAE) model of MS. Approximately, 50\% of 2D2 $\left(\mathrm{TCR}^{\mathrm{MOG}}\right) \times \mathrm{Th}\left(\mathrm{IgH}^{\mathrm{MOG}}\right)$ mice develop spontaneous chronic EAE and exhibit meningeal clusters of $T$ and $\mathrm{B}$ cells in the spinal cord, reminiscent of those found in MS. $^{23-25}$

In this model, we depleted B cells to investigate whether $\mathrm{aCD} 20 \mathrm{mAb}$ prevents mELT formation. Surprisingly, our results showed that, despite depleting virtually all B cells from the meninges, mELT still formed or persisted.

\section{Materials and Methods}

\section{Mice}

2D2xTh mice, developing spontaneous chronic EAE with mELT, were generated as previously described by crossing myelin oligodendrocyte glycoprotein (MOG)-specific T-cell receptor (TCR) transgenic 2D2 (TCR ${ }^{\mathrm{MOG}}$ ) mice with MOG-Bcell receptor $(\mathrm{BCR})$ knockin Th mice $\left(\mathrm{IgH}{ }^{\mathrm{MOG}}\right){ }^{23,24}$ Mice were bred and maintained in-house at the Center of Preclinical Research (CPR) at Klinikum rechts der Isar (Technical University of Munich) under specific pathogen-free conditions, according to FELASA recommendations with free access to water and standard rodent chow.

\section{EAE and Clinical Assessment}

$2 \mathrm{D} 2 \mathrm{xTh}$ mice develop spontaneous chronic EAE with an incidence of approximately $30-50 \%$ in our facility. Clinical scores of mice were evaluated on a daily basis and assessed as follows: $0=$ no clinical signs, $1=$ tail weakness, $1.5=$ additional impaired tail erection, $2=$ ataxia and hind limb weakness, $2.5=$ hind limb paresis, $3=$ high-grade hind limb paresis, 3.5 = additional minor weakness of the fore limbs, $4=$ additional fore limb paresis, $4.5=$ tetraplegia, and $5=$ moribund.

\section{aCD20 mAb Treatment}

$100 \mu \mathrm{g}$ of antimouse $\mathrm{CD} 20 \mathrm{mAb}$ (clone $18 \mathrm{~B} 12$, provided by $\mathrm{F}$. Hoffmann-La Roche, Switzerland) in a murine IgG2a Fcformat or antihen egg lysozyme isotype control (Crown bio, Cat: C0006) in $100 \mu \mathrm{L}$ PBS was injected intraperitoneally (i.p.) at day $0,7,14$, and 21 for a total of 4 doses. Mice were grouped for prevention or treatment of EAE. In an attempt to prevent EAE, mice received the first injection at the age of $26 \pm 3$ days ( $\mathrm{n}=18$ in both groups). For the evaluation of the therapeutic potential, mice were treated when reaching a clinical score of $\geq 3$ ( $\mathrm{n}=11 \mathrm{aCD} 20 \mathrm{mAb}$-treated, $\mathrm{n}=14$ isotype-treated). Mice were killed 28 days after the first injection. Reference mice at the onset of disease (figure 3C) were dissected immediately after reaching an EAE score of $\geq 3$ without treatment.

\section{Cell Isolation and Flow Cytometric Analysis}

Blood was freshly obtained by terminal cardiac puncture and mixed with $500 \mu \mathrm{L} 2 \mathrm{mM}$ EDTA. Cervical lymph nodes were carefully dissected and passed through a $30-\mu \mathrm{m}$ cell strainer. Samples were washed with RPMI medium, and erythrocytes were lysed using BD Pharm Lyse Buffer (BD Biosciences). Cells were washed again, and the number of living cells was determined using a hemocytometer (Cellometer Auto 2000, Nexcelom Bioscience). Single-cell suspensions were stained with antibodies in PBS containing 2\% fetal calf serum for 20 
A

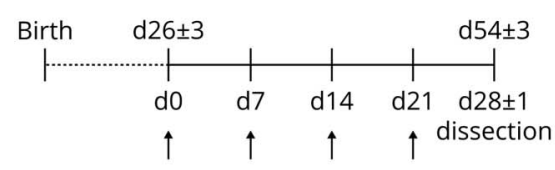

$100 \mu \mathrm{g}$ i.p.

B.a
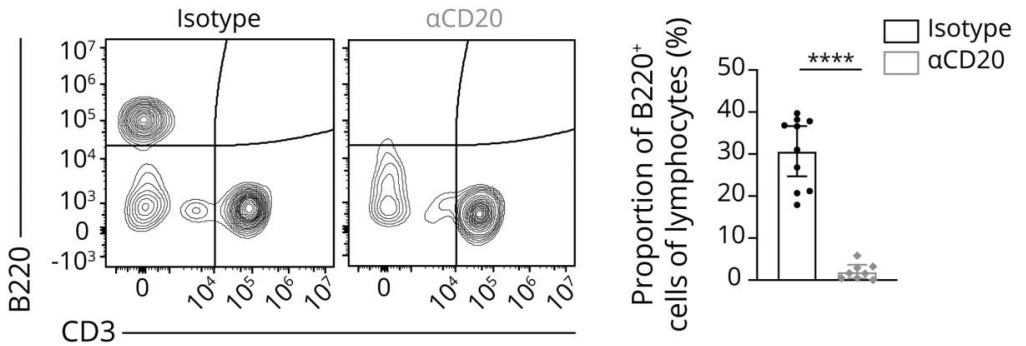

B.b
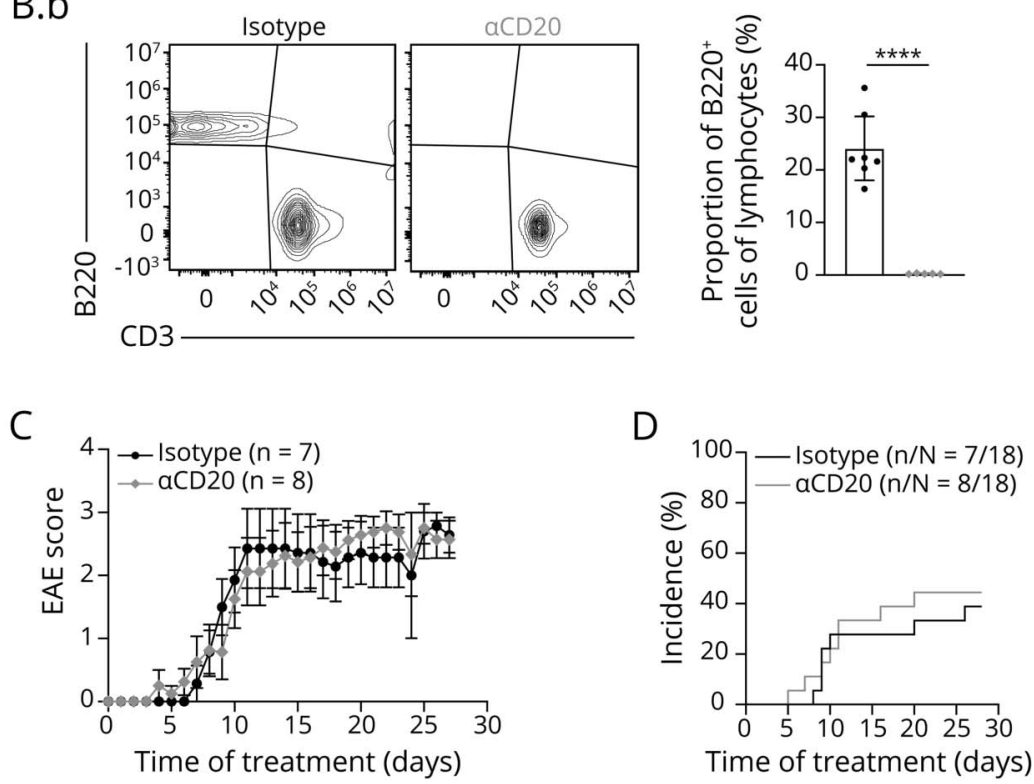

(A) Experimental setup. Mice were treated with a weekly dose of $100 \mu \mathrm{g}$ of aCD20 mAb $(n=18)$ or isotype control $(n=18)$ after weaning. (B) Flow cytometric analysis of B220+ and CD3 ${ }^{+}$cells in blood (B.a) and lymph nodes (B.b) after 4 weeks of treatment. The representative flow cytometry contour plot (left) and quantification (right). (C) Daily evaluated EAE scores over the experimental period. Data are shown as mean \pm SEM. (D) Incidence of mice developing clinical signs of disease. When not stated differently, data shown as mean $\pm 95 \% \mathrm{Cl}$. ${ }^{*} p<0.05$; $* \star \star \star * p<0.0001$; statistical significance between groups was analyzed using the Student $t$ test. aCD20 mAb = anti-CD20 monoclonal antibody: $\mathrm{EAE}=$ experimental autoimmune encephalomyelitis; i.p. = intraperitoneally; $n / N$ $=$ mice with EAE/all mice observed. minutes at $4^{\circ} \mathrm{C}$ in the dark. Fc-receptors were blocked to prevent nonspecific antibody binding. Dead cells were excluded using the LIVE/DEAD Fixable Aqua Dead Cell Stain Kit (Invitrogen). Cells were washed twice and acquired on a CytoFLEX flow cytometer (Beckman Coulter). The following antimouse antibodies were used: CD16/CD32 (2.4G2), CD45R/B220 (RA3-6B2, FITC), and CD3e (145-2C11, PE) (BD Bioscience). Data were analyzed using FlowJo version 10 (TreeStar).

\section{Histology, Immunohistochemistry, and Imaging}

Spinal cord, spleen, and inguinal lymph nodes were perfused before dissection, fixed with $4 \%$ paraformaldehyde, and paraffin embedded. The spinal cord was additionally decalcified with Osteosoft (Sigma-Aldrich) 72 hours before embedding. To determine the degree of meningeal infiltrates, the spinal cord was sectioned horizontally into 13-16 tissue blocks (thickness: $2 \times 5 \mathrm{~mm}$ cervical, subsequently $2.5 \mathrm{~mm}$ ) per mouse and stained with hematoxylin and eosin according to standard protocols. The stained tissues were digitized (Leica AT2 scanner) and examined using Image Scope (Pathology Slide Viewing Software, version 12.4.3, Leica Biosystems). Infiltrates with a size of $\geq 1 \times 10^{4} \mu \mathrm{m}^{2}$ per section were considered as mELT. The cell density was analyzed using a nuclear algorithm (Nuclear v9, Image Scope; Leica). To characterize the cellular composition of mELT, immunohistochemistry was performed on representative sections with antimouse CD45R/B220 (BD, 550286, 1:50), CD3 (DCS, CI597R0, 1:50), and myeloperoxidase (MPO; Thermo Fisher, RB-373-A, 1:50). Mouse spleens served as positive

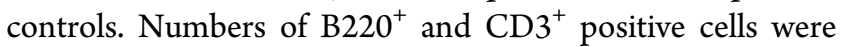
determined using a membrane algorithm (Membrane v9, Image Scope; Leica). In the CNS, $\mathrm{MPO}^{+}$cells were counted 

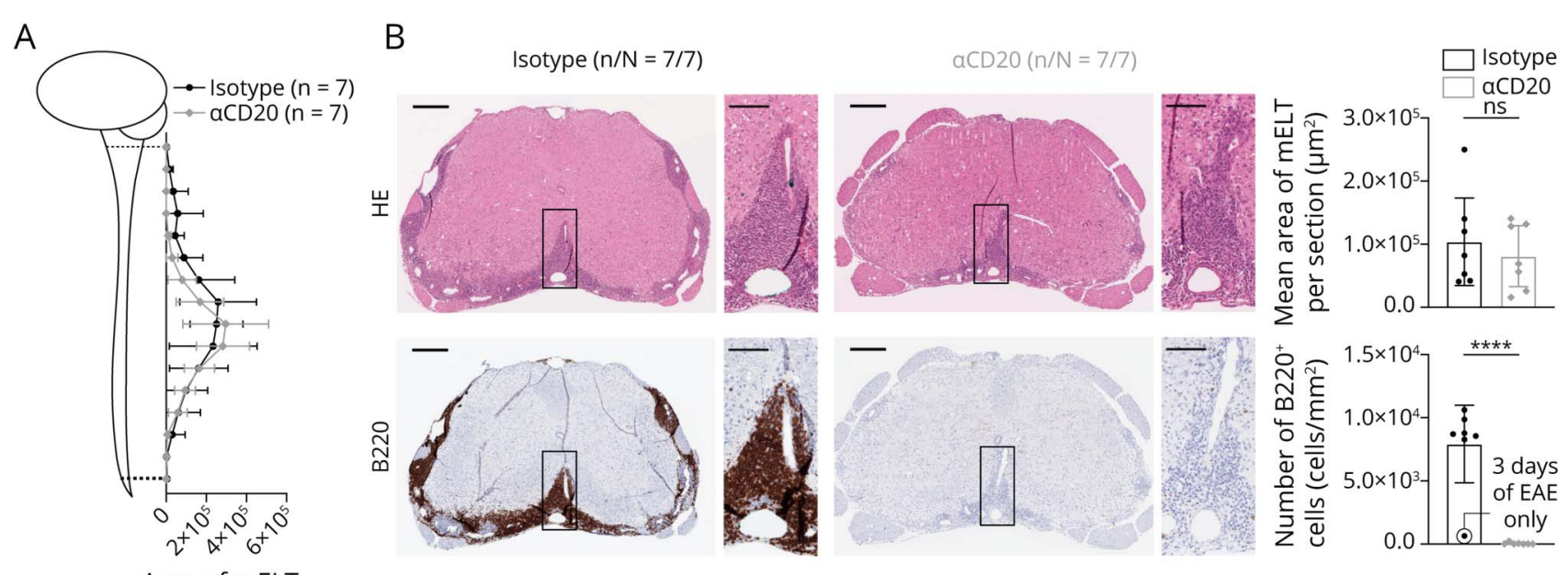

Area of $\mathrm{mELT}$

per section $\left(\mu \mathrm{m}^{2}\right)$

C
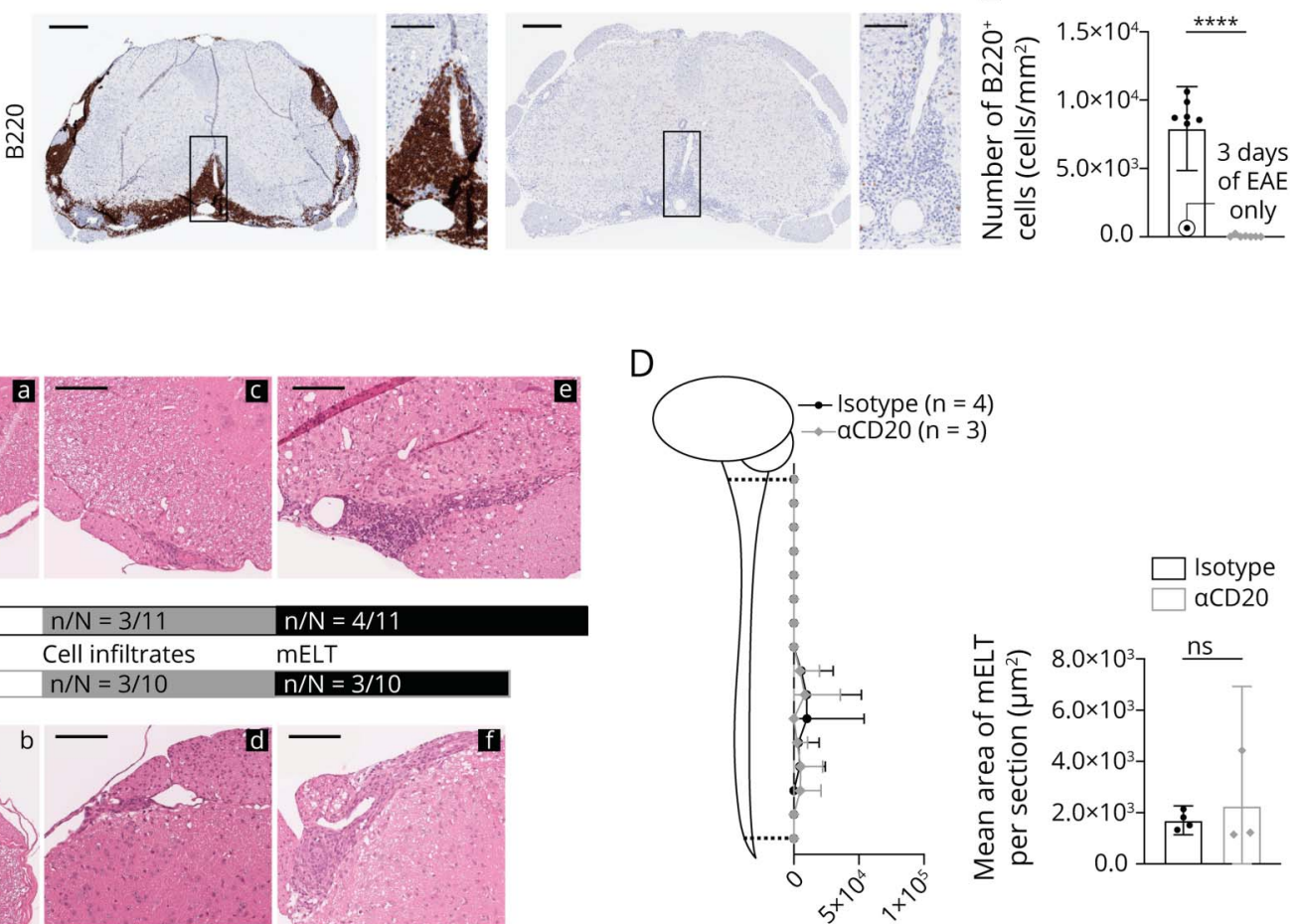

Area of $\mathrm{mELT}$

per section $\left(\mu \mathrm{m}^{2}\right)$

After weaning, 2D2xTh mice received a weekly dose of $100 \mu \mathrm{gaCD} 20 \mathrm{mAb}(\mathrm{n}=18)$ or isotype control mAb $(n=18)$ and were observed for 28 days $(A+B) 8$ of 18 aCD20 mAb-treated mice and 7 of 18 isotype mAb-treated mice developed EAE. One aCD20 mAb-treated mouse died prematurely and had to be excluded from the histologic analysis. (A) Quantitative distribution of mELT along the spinal cord with 12-16 cross-sections per animal analyzed. (B) Representative HEstained (upper left panel) and B220-stained (lower left panel) sections of the thoracolumbar part of the spinal cord and corresponding close-up views of mELT. Quantification of the mean area of mELT including all sections (upper right panel) and the number of $\mathrm{B} 22 \mathrm{O}^{+}$cells in mELT, analyzed in 2 randomly selected sections per animal, for all mice (lower right panel). (C) Analysis of histologic signs of disease in mice without clinically manifest EAE (11 of 18 isotype mAbtreated mice and 10 of 18 aCD20 mAb-treated mice). Representative HE sections given in (a) and (b) for mice with no pathologies, in (c) and (d) for mice with minor cellular infiltrates in the meninges, and in (e) and (f) for mice with mELT. (D) Quantitative analysis of the size and distribution of mELT along the spine in mice without clinically manifest EAE. In total, 12-16 sections analyzed per animal. Scale bars: $250 \mu \mathrm{m}$ (overviews) and $100 \mu \mathrm{m}$ (close-ups). When not stated

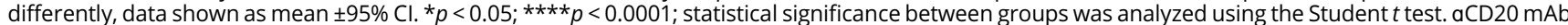
= anti-CD20 monoclonal antibody; EAE = experimental autoimmune encephalomyelitis; $\mathrm{HE}$ = hematoxylin \& eosin; mELT = meningeal ectopic lymphoid tissue; $\mathrm{n} / \mathrm{N}=$ mice showing mELT or noted feature/total number of mice analyzed; $\mathrm{ns}=$ not significant.

manually. In the periphery, $\mathrm{MPO}^{+}$cells were quantified by applying a nuclear algorithm (Membrane v9, Image Scope; Leica). Two cross-sections of the cervicothoracic, the thoracolumbar, and the lower lumbar part were stained with Luxol fast blue and periodic acid-Schiff reaction (LFB-PAS) according to standard protocols. LFB-PAS staining was analyzed semiquantitatively by dividing spinal cord sections into quadrants and counting quadrants with demyelination. All histologic evaluations were performed in a blinded manner.

\section{Detection of Anti-MOG Antibodies}

Antirecombinant mouse MOG (1-125) (Eurogentec, Cat: AS-55150-100) IgG was measured with a noncommercial
ELISA in duplicates as described, ${ }^{26}$ using MOG at a final concentration of $10 \mu \mathrm{g} / \mathrm{mL}$ and horseradish peroxidaselabeled goat antimouse IgG (Thermo Fisher Scientific). The optical density was measured at a wavelength of $450 \mathrm{~nm}$ with $540 \mathrm{~nm}$ as a reference wavelength using the ELISA reader (infinite M200 PRO, TECAN).

\section{Statistical Analysis}

Data are shown as mean \pm SEM or 95\% CI. Statistical significance between groups was analyzed using the unpaired Student $t$ test. For correlation analysis, simple linear regression was calculated for each group. A value of $p \leq 0.05$ was considered significant with ${ }^{*} p<0.05,{ }^{* *} p<0.01,{ }^{* * *} p<0.001$, and ${ }^{* * * *} p<0.0001$. 


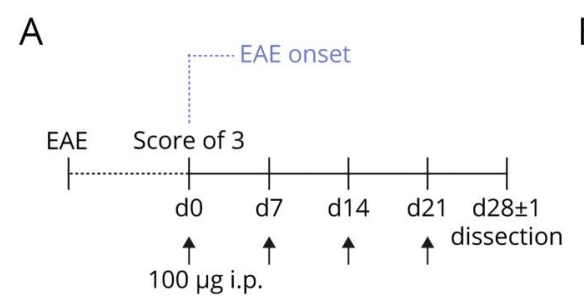

D

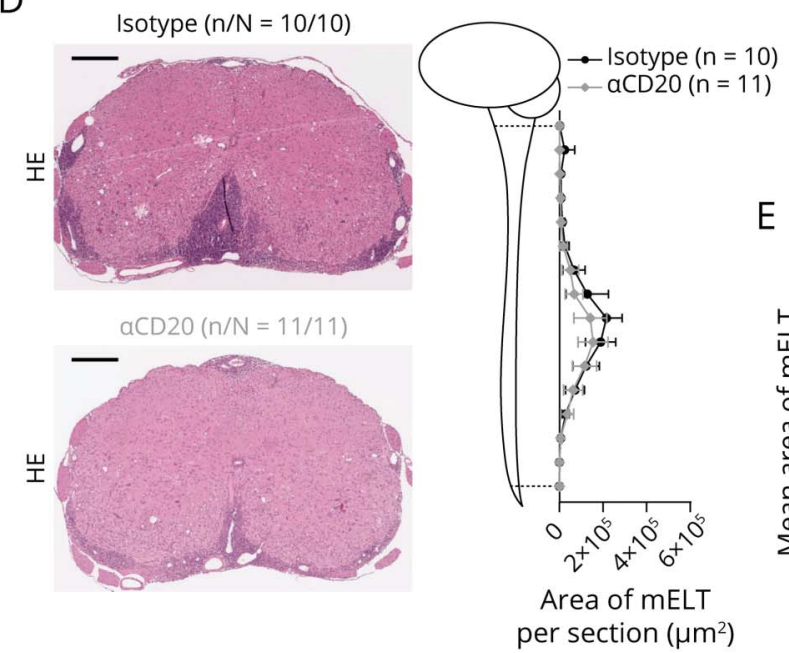

B Start treatment

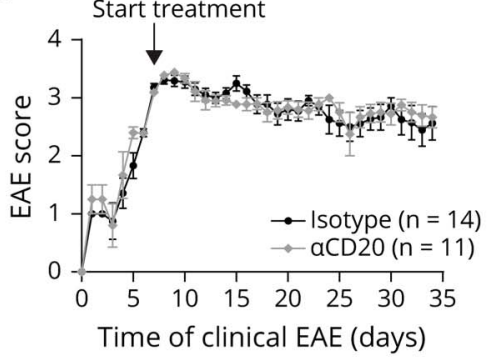

C
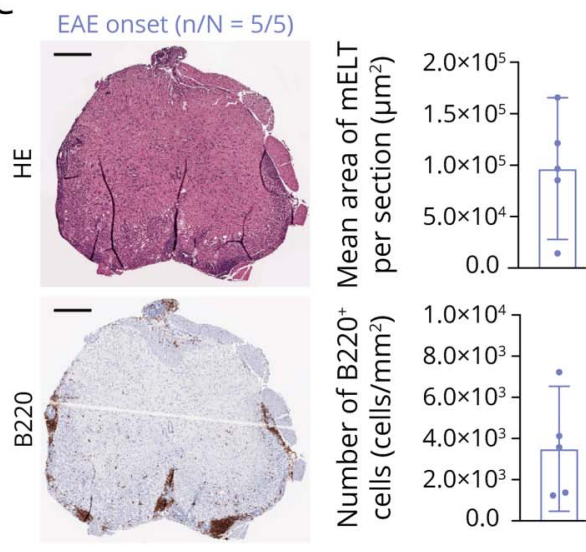

$\mathrm{F}$

Isotype $(p=0.0111, r=0.5747)$

$\operatorname{aCD20}(p=0.1705, r=0.1978)$

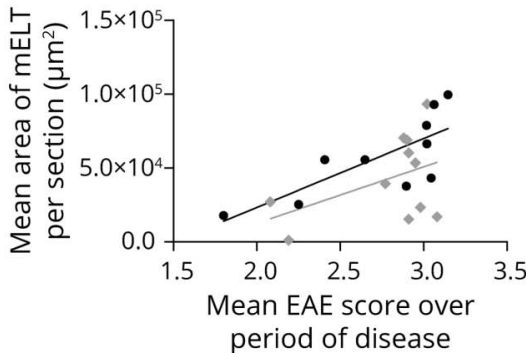

(A) Experimental setup. As soon as 2D2xTh mice developed a score of $\geq 3$, they received a weekly dose of $100 \mu g$ of aCD20 ( $n=11)$ or isotype control $m A b$ ( $n=$ 14) over a period of 28 days. Another 5 mice were euthanized and dissected directly after developing a clinical score of $\geq 3$, without receiving treatment. They served as histologic reference at disease onset for the remainder of the mice for which treatment commenced at that stage. (B) Clinical course of EAE during application of aCD20 or isotype mAb. Data expressed as mean \pm SEM. (C) Representative HE (upper left panel) and B220 (lower left panel) staining of the spinal cord mELT of mice at EAE onset and respective quantification in all mice (right panels). (D) Representative HE-stained cross-sections of the thoracolumbar part of the spinal cord of aCD20 mAb-treated and isotype-treated mice (left) and representation of the distribution of mELT along the spine with 14-16 sections analyzed per animal (right). (E) Quantification of the mean area of mELT per section. (F) Correlation of the mean area of mELT per section with the mean EAE score over the observation period. Simple linear regression was calculated for each group. Scale bars, $250 \mu \mathrm{m}$. When not indicated differently, data shown as mean $\pm 95 \% \mathrm{Cl}$. Statistical significance between groups was analyzed using the Student $t$ test. aCD20 mAb $=$ anti-CD20 monoclonal antibody; EAE $=$ experimental autoimmune encephalomyelitis; $\mathrm{HE}=$ hematoxylin \& eosin; i.p. = intraperitoneally; mELT = meningeal ectopic lymphoid tissue; $\mathrm{n} / \mathrm{N}=$ mice showing $\mathrm{mELT} /$ total number of mice analyzed; ns = not significant.

\section{Standard Protocol Approvals, Registrations, and Patient Consents}

All animal experiments were approved by the competent authority, Regierung von Oberbayern, Munich, Germany (ROB55.2-2532.Vet_02-16-100).

\section{Data Availability}

Data not published within this article will be made available by request from any qualified investigator.

\section{Results}

\section{aCD20 mAb Efficiently Depletes B Cells in the Periphery but Does Not Affect the Clinical Course of Spontaneous Chronic EAE}

To analyze the effects of aCD20 mAb on mELT in the context of EAE, we crossed MOG Ig-VH knock-in $\left(\mathrm{IgH}^{\mathrm{MOG}}\right.$, Th) mice, in which B cells express a MOG-specific BCR heavy chain, with MOG-specific TCR transgenic mice $\left(\mathrm{TCR}^{\mathrm{MOG}}\right.$,
2D2). As previously described, 2D2xTh mice develop spontaneous chronic EAE with B-cell-rich and T-cell-rich mELT along the spinal cord. ${ }^{23,24}$

2D2xTh mice were treated weekly for a total of 4 intraperitoneal (i.p.) doses with antimurine $\mathrm{CD} 20$ or isotype control $\mathrm{mAb}$. Two treatment paradigms were pursued in parallel: (1) to prevent EAE and mELT formation, mice received the first dose as soon as they were weaned about 26 days after birth (figure 1A) and (2) to treat fully established EAE, aCD20 mAb was first administered after mice developed an EAE score of $\geq 3$ (figure $3 \mathrm{~A}$ ). aCD20 mAb efficiently depleted B cells in the peripheral blood (figure 1B.a, upper panel) and lymph nodes (figure 1B.b, lower panel). However, its application neither attenuated the rather severe and chronic course of EAE compared with the control groups in either condition (figures $1 \mathrm{C}$ and $3 \mathrm{~B}$ ) nor changed the incidence of EAE. In total, $44 \%$ of preventatively treated mice developed spontaneous chronic EAE, which was similar to $39 \%$ of control treated mice (figure 1D). 
Figure 4 B-Cell-Depleted Spontaneous Chronic EAE Mice Exhibit High Titers of Anti-MOG Antibodies and Extensive Demyelination, Reflecting Their Severe Disease Course
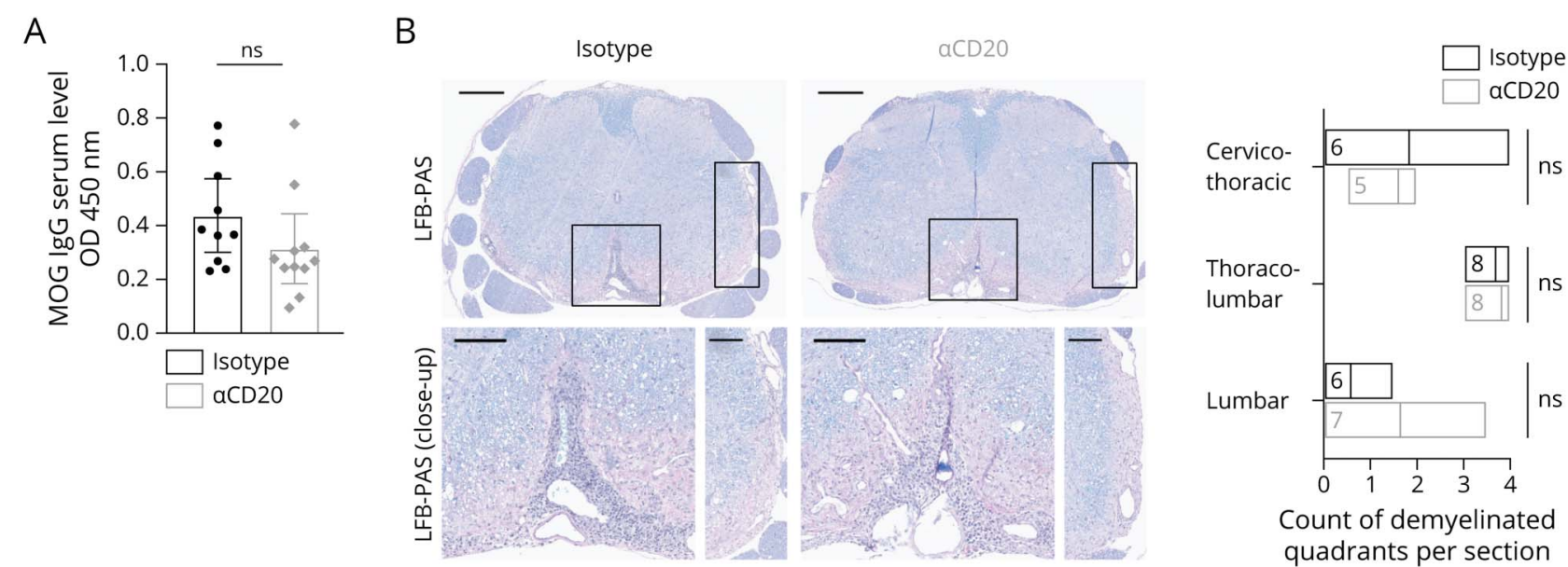

Count of demyelinated quadrants per section

2D2xTh mice received 4 doses of aCD20 mAb $(n=11)$ or isotype control $(n=10)$ as soon as they reached an EAE score of $\geq 3$. (A) Antimurine MOG IgG serum levels determined by ELISA (dilution 1:300). Data are shown as individual data points and mean $\pm 95 \%$ Cl. (B) LFB-PAS staining of the spinal cord, showing representative thoracolumbar cross-sections and corresponding close-ups. For each mouse, 2 randomly chosen cross-sections per spinal cord segmentcervicothoracic ( $n=5$ for aCD20 mAb and $n=6$ for isotype), thoracolumbar ( $n=8$ per group), and lumbar ( $=7$ for aCD20 $m A b$ and $n=6$ for isotype) - were examined. Data are presented as minimum and maximum values and mean. Scale bars: $250 \mu \mathrm{m}$ and $100 \mu \mathrm{m}$ (close-ups). Statistical significance between groups was analyzed using the Student $t$ test. aCD20 mAb = anti-CD20 monoclonal antibody; EAE = experimental autoimmune encephalomyelitis; LFB-PAS = Luxol fast blue and periodic acid-Schiff reaction; MOG = myelin oligodendrocyte glycoprotein; ns = not significant; OD = optical density.

\section{mELT Formation and Retention Occurs in the Absence of B Cells in Preventatively Treated Mice}

To investigate whether mELT forms and persists under B-celldepleting conditions, we analyzed cross-sections along the spinal cord of $2 \mathrm{D} 2 \mathrm{xTh}$ mice, which developed clinical signs of EAE during the observation/treatment period. With a mean EAE duration of 19 days (range 13-24 days) in the aCD20 mAbtreated group and 16 days (range 3-21 days) in the isotypetreated group, all mice showed mELT in at least 5 of 12-16 segments with a maximum along the thoracolumbar part of the spinal cord (figure $2 \mathrm{~A}$ ). Infiltrates were considered as mELT when their size was $\geq 1 \times 10^{4} \mu \mathrm{m}^{2}$ per section. Surprisingly, the mean area of mELT per section, including sections in which no mELT was detected, was similar in both groups with a mean of $81,152 \mu \mathrm{m}^{2}$ per section in aCD20 mAb and 103,968 $\mu \mathrm{m}^{2}$ in isotype-treated controls (figure $2 \mathrm{~B}$, upper panel). Hence, despite the absence of $\mathrm{B}$ cells in circulation and cervical lymph nodes, structures of mELT formed. With B cells being a main component of $\mathrm{mELT}^{21,23,24}$ we performed B220 immunohistochemistry on sections of the thoracolumbar part of the spinal cord. We found that, although mELT was present to a similar extend, mELT of aCD20 mAb-treated mice only exhibited $0.59 \%$ of $\mathrm{B} 220^{+} \mathrm{B}$ cells observed in controls (figure $2 \mathrm{~B}$, lower panel).

Interestingly, in both groups, mice without clinically apparent EAE over the treatment period of 28 days also showed histologic signs of disease in approximately $60 \%$ of cases, ranging from scattered cellular infiltrates in the meninges in some cases to $\mathrm{mELT}$ in $30 \%$ of the aCD20 mAb-treated mice and $36 \%$ of the isotype controls (figure $2 \mathrm{C}$ ). In these clinically unremarkable animals, mELT was also mainly found in the thoracolumbar part of the spinal cord and was comparable in size in both groups (figure 2D).

Our data indicate that the absence of B cells in preventatively treated $2 \mathrm{D} 2 \mathrm{xTh}$ mice is not sufficient to prevent mELT formation and that not only mELT formation but also its retention may be independent of B cells. Moreover, mELT formation in our model occurs before developing clinical signs of EAE.

\section{aCD20 mAb Treatment Does Not Influence the Size of $\mathrm{MELT}$}

In a second experiment, more closely resembling a clinical scenario, mice were randomized into groups treated with aCD20 or control mAbs after disease onset, i.e., when having developed an EAE score of $\geq 3$ (aged on average 47.6 days in the aCD20 $\mathrm{mAb}$ and 48.4 days in the isotype-treated group). As a baseline, we used mice which were euthanized without further treatment immediately after having developed a score of $\geq 3$ (figure $3 \mathrm{~A}$ ). At that stage of disease (onset), all mice already exhibited extensive mELT with a distinct fraction of $\mathrm{B}_{2} 20^{+} \mathrm{B}$ cells (figure $3 \mathrm{C}$ ), confirming that mELT was sufficiently present before we started our intervention. After 4 weeks of treatment, distribution of mELT throughout the spinal cord was almost identical in-between groups, with all mice exhibiting mELT in at least 1 of 14-16 cross-sections analyzed (figure 3D). Again, we did not observe a difference in the mean area of mELT in both groups (figure 3E). Similar to what was observed in autopsy cases of MS, the extent of mELT correlated with disease severity in control mice. However, this was not statistically significant in aCD20 mAbtreated animals (figure $3 \mathrm{~F}$ ). 

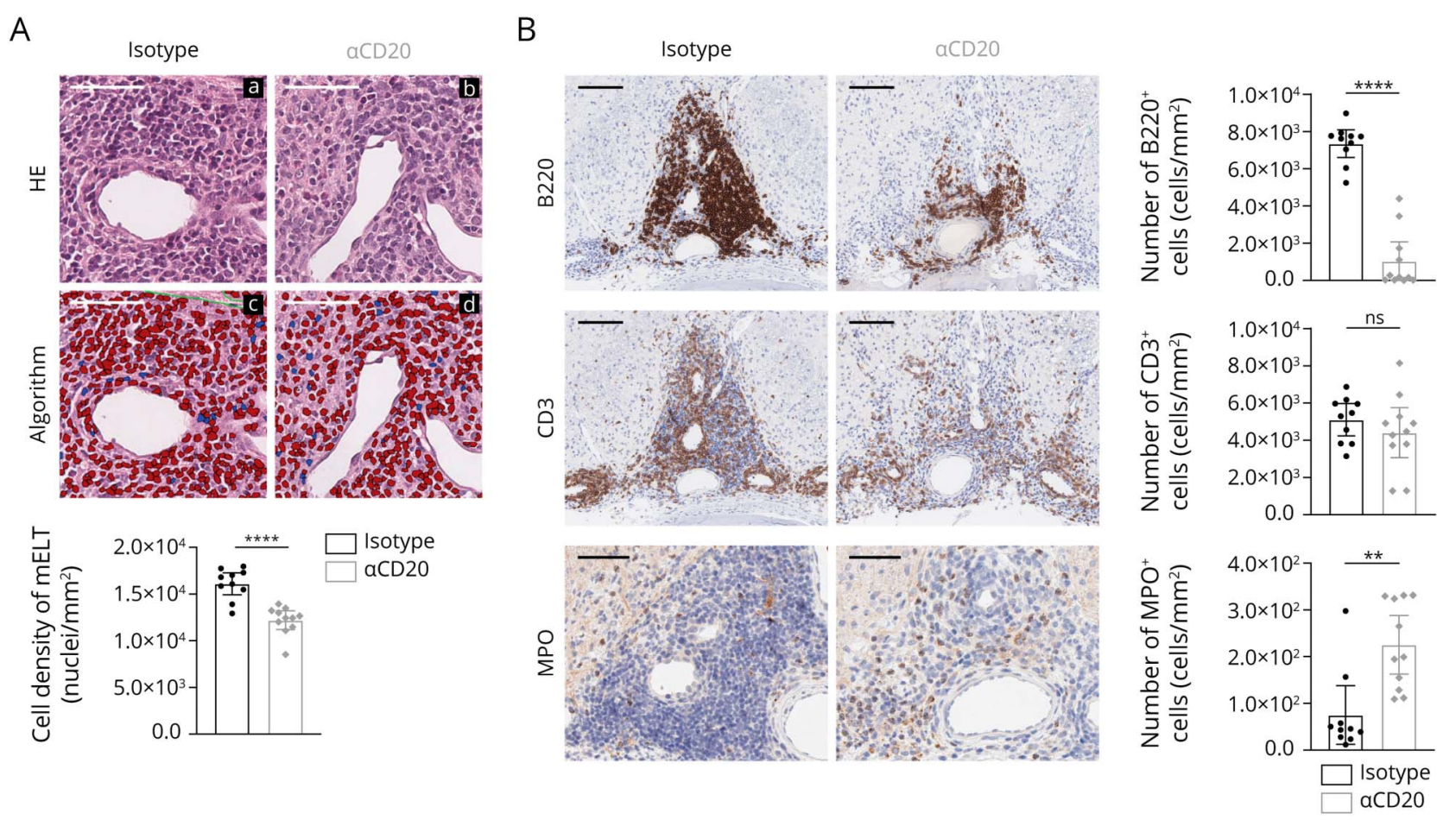

2D2xTh mice received 4 doses of aCD20 mAb $(n=11)$ or isotype control $(n=10)$ as soon as they reached an EAE score of $\geq 3$. (A) HE staining of representative spinal cord sections of (a) isotype-treated and (b) aCD20 mAb-treated mice visualizing the cellular density of mELT (c) and (d) show representative samples of the computer-aided quantification of nuclei in mELT with the corresponding graphs. (B) Quantification of B cells (B220), T cells (CD3), and neutrophil granulocytes (MPO) in spinal cord mELT. mELT of 1-4 randomly chosen cross-sections per mouse were analyzed. Scale bars: $50 \mu \mathrm{m}$ (A) and $100 \mu \mathrm{m}$ (B). Data are presented as individual data points and mean $\pm 95 \% \mathrm{Cl}$. ${ }^{*} p \leq 0.05 ; * \star p<0.01 ; * \star \star \star * p<0.0001$; statistical significance between groups was analyzed using the Student $t$ test. aCD20 mAb = anti-CD20 monoclonal antibody; EAE = experimental autoimmune encephalomyelitis; HE = hematoxylin \& eosin; mELT = meningeal ectopic lymphoid tissue; MPO = myeloperoxidase; ns = not significant.

\section{Persisting High Titers of Anti-MOG Antibodies and Extensive Demyelination in B-Cell- Depleted Mice Reflects the Lasting Severe and Chronic Course of EAE}

Although B cells were effectively reduced not only in the periphery but also in the meningeal compartment, MOGspecific total IgG titers remained high even after 4 weeks of B-cell depletion (figure 4A). Correlating with the clinical disease course, the spinal cord was similarly affected by demyelination in aCD20 mAb-treated mice compared with controls (figure 4B). Together with persisting B-cell-free mELT, these observations may contribute to the lack of a clinical benefit of B-cell depletion in our model.

\section{aCD20 mAb Treatment Changes the Density and Composition of the Cellular Content of $\mathrm{MELT}$}

When we analyzed the cellular composition of MELT more closely, we found that, within the treatment paradigm, mELT in aCD20 mAb-treated mice was populated with $24.2 \%$ less cells (figure 5A). The count of $\mathrm{B}^{2} 20^{+} \mathrm{B}$ cells, which was the largest immune cell fraction in control mice, was drastically reduced on aCD20 $\mathrm{mAb}$ treatment, suggesting that the absence of $B$ cells led to this reduced cellular density in mELT (figure 5B, upper panel). We did not notice a relevant change in $\mathrm{CD}^{+}$cells (figure $5 \mathrm{~B}$, middle panel), whereas the number of MPO positive neutrophil granulocytes was significantly increased under $\mathrm{aCD} 20 \mathrm{mAb}$ therapy (figure $5 \mathrm{~B}$, lower panel). Comparing these changes in mELT with SLOs, we observed that in the spleen and inguinal lymph nodes, $\mathrm{B} 220^{+}$ $\mathrm{B}$ cells were also largely eliminated. $\mathrm{MPO}^{+}$cells seemed to be increased, but this did not reach statistical significance. In contrast to $\mathrm{mELT}$, however, the amount of $\mathrm{CD}^{+} \mathrm{T}$ cells was slightly increased in B-cell-depleted lymph nodes (figure 6).

Together, our findings show that aCD20 mAb, to some degree, depletes $B$ cells in mELT in mice with spontaneous chronic EAE, yet mELT persists. The role and function of mELT devoid of $B$ cells remains unclear.

\section{Discussion}

Although its exact role in MS pathogenesis remains unclear, meningeal inflammation has gained widespread attention in recent years. Because B cells are a major component of mELT and B-cell-depleting $\mathrm{mAbs}$ are among the most successful MS therapeutics today, the question how B-cell-depleting therapies affect mELT is obvious. In this study, we systematically addressed this question in a murine model of MS. 


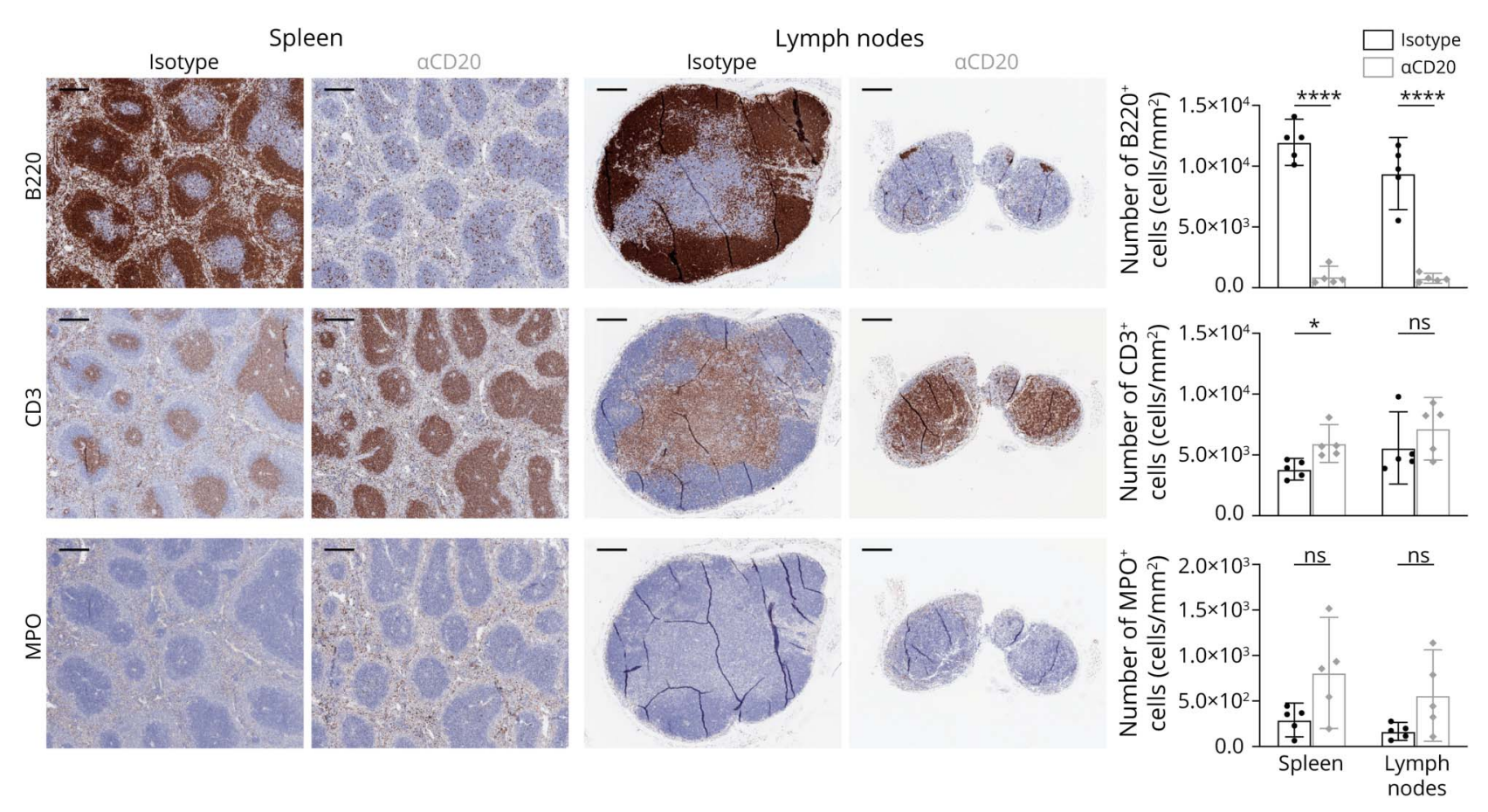

2D2xTh mice received 4 doses of aCD20 mAb $(n=11)$ or isotype control $(n=10)$ as soon as they reached an EAE score of $\geq 3$. Quantification of B cells (B220), T cells (CD3), and neutrophil granulocytes (MPO) in spleens and inguinal lymph nodes. One randomly chosen cross-section per organ ( $n=5$ mice per group) was evaluated. Scale bars: $250 \mu \mathrm{m}$. Data are presented as individual data points and mean $\pm 95 \% \mathrm{Cl}$. ${ }^{*} p \leq 0.05$; $* \star \star * p<0.0001$; statistical significance between groups was analyzed using the Student $t$ test. aCD20 mAb = anti-CD20 monoclonal antibody; EAE = experimental autoimmune encephalomyelitis; LN = lymph node; MPO = myeloperoxidase; ns = not significant; SLO = secondary lymphoid organ; SPL = spleen.

Not unexpectedly, B-cell depletion did not change the disease course in our spontaneous chronic EAE model. It has previously been reported that aCD20 mAb did not significantly change the course of EAE in the same model because high titers of MOG-binding antibodies in conjunction with $\mathrm{MOG}^{\mathrm{TCR}} 2 \mathrm{D} 2 \mathrm{~T}$ cells could support clinical disease in the absence of $\mathrm{B}$ cells. ${ }^{26}$ Importantly, aCD20 mAb does not target antibody-producing plasma cells. It could be debated that spontaneous chronic EAE in 2D2xTh mice, because of the MOG specificity of both $\mathrm{T}$ and $\mathrm{B}$ cells, is not dynamic enough to allow being modified by pharmaceutical interventions. However, laquinimod ameliorated spontaneous chronic EAE and reduced meningeal B-cell aggregates and thereby demonstrated its plasticity. ${ }^{27}$ Thus, other factors are likely to contribute.

Although clinical effects were neglectable, we found that aCD20 mAb depleted virtually all B cells not only from SLOs and blood but also from mELT. It has been shown before that $B$ cells infiltrating the meninges in EAE could be efficiently depleted by aCD20 mAb administered either intraperitoneally or intrathecally. ${ }^{22}$ This study used a model, however, which does not feature large meningeal B-cell aggregates such as mELT. A case report of a patient with gastrointestinal mantle cell lymphoma, who developed progressive multifocal leukoencephalopathy after rituximab therapy, showed that 8 months after the last dose, no B cells were found in perivascular spaces. ${ }^{28}$ By contrast, a case report of a young man with aggressive MS treated with rituximab and with no detectable peripheral B cells found some B cells in the parenchyma and in perivascular cuffs on CNS autopsy. ${ }^{29}$ Regarding B-cell-depleting antibodies used to treat MS, it is an encouraging finding that aCD20 mAb could deplete B cells present in $\mathrm{mELT}$ and prospectively prevent colonization of the meningeal compartment by B cells. Yet, open questions remain.

The most unexpected finding in our study was that mELT formed or remained in the absence of B cells when mice were B-cell-depleted after EAE was fully established and even when treated before EAE onset. The size and extent of mELT was even comparable whether they contained B cells or not. This shows that, in our model, B cells are not essential for the induction or maintenance of mELT development. Yet, in the absence of B cells, mELT was less densely packed with cells and the cellular composition was altered. aCD20 mAbtreated mice had drastically fewer $\mathrm{B} 220^{+} \mathrm{B}$ cells, comparable amounts of $\mathrm{CD}^{+} \mathrm{T}$ cells, and significantly more $\mathrm{MPO}^{+}$ neutrophil granulocytes in mELT. A recent study showed that neutrophil granulocytes pioneer mELT formation and precede $\mathrm{B}$ cells in the meningeal compartment. ${ }^{30}$ In addition, several other cell types have been proposed as candidates to induce ELT formation, including IL-22 or IL-17 secreting immune cells, dendritic cells, and $\mathrm{CD} 3^{-} \mathrm{CD} 4^{+} \mathrm{CD} 45^{+}$ 
lymphoid tissue inducer cells. ${ }^{16,31-35}$ Our own data showed that shortly after EAE onset, B220 ${ }^{+}$B cells were already present in $\mathrm{mELT}$, but after 4 weeks of isotype control treatment, their amount had roughly doubled. Thus, B cells seem to fully populate mELT at later stages. This raises the question, which role B cells play in (later stage) mELT and whether $\mathrm{mELT}$ without $\mathrm{B}$ cells still has a pathogenic role. Generally, our mice would be expected to benefit from B-cell depletion, like it has been shown in another B-cell-dependent model without mELT or in MS itself. ${ }^{1-3,36}$ If mELT lacking $B$ cells still contribute to autoimmunity, this could explain why the EAE disease course is unchanged in aCD20 mAb-treated $2 \mathrm{D} 2 \mathrm{xTh}$ mice. As discussed above, other inherent properties of the model could contribute, such as the presence of high titers of MOG-binding antibodies and $\mathrm{MOG}^{\mathrm{TCR}} \mathrm{T}$ cells with a potentially altered activation status under aCD20 $\mathrm{mAb}$ therapy. However, the notion that mELT without B cells persist in EAE and its persistence correlates with sustained severe disease, may give rise to interesting considerations: B-cell-depleting therapies are disproportionately more effective in RRMS than PMS. It could be speculated that future therapeutic approaches targeting mELT directly, instead of $\mathrm{B}$ cells, may be more effective in treating PMS.

We observed that approximately one-third of 2D2xTh mice without clinically manifest EAE develop a minor degree of mELT both in the presence or absence of B cells. What does this imply regarding the role of mELT? Naturally, it remains unknown whether for these mice disease was imminent and the occurrence of mELT only preceding clinical signs. Alternatively, it is possible that $2 \mathrm{D} 2 \mathrm{xTh}$ mice live with mELT without developing a phenotype. The latter would suggest that mELT may be a rather irrelevant epiphenomenon of encephalitogenic $\mathrm{B}$ and $\mathrm{T}$ cells being present in this model or that mELT may even have a regulatory role.

One limitation of our study is that we depleted B cells relatively soon, i.e., before the onset of EAE or at an early stage of disease, where B cells are already present in MELT but to a lesser extent. We believe that it is reasonable to conclude from our results that $B$ cells already present in $\mathrm{mELT}$ were depleted by aCD $20 \mathrm{mAb}$. However, we could not formally assess the respective contributions of preventing B-cell influx from the periphery or direct depletion in the CNS itself to our finding that mELT was devoid of B cells after several weeks of treatment with aCD20 $\mathrm{mAb}$.

It is very challenging to study meningeal pathologies in patients in vivo or even postmortem. Thus, animal models are instrumental, and yet, the transferability of any findings in such models to MS must be questioned continuously. Our model of spontaneous chronic EAE has several characteristics that make it a suitable tool. EAE develops without an external stimulus, such as immunization or an adjuvant, and mice form meningeal inflammatory aggregates. Furthermore, mELT is readily available in high quality and quantity. However, it is a highly artificial model which is genetically determined through B-cell-mediated and T-cell-mediated autoimmunity against MOG. MS, by contrast, is not known to have a single autoantigen and certainly does not feature such a highly polarized adaptive immune system. Therefore, studies in human subjects treated with $\mathrm{aCD} 20 \mathrm{mAb}$ are required to confirm our results.

In conclusion, we provide evidence that systemically applied aCD20 mAbs efficiently deplete B cells in meningeal inflammatory aggregates, and yet, mELT still form and persist with an altered cellular composition. The unchanged severe course of EAE, despite near complete B-cell depletion, both in the periphery and the meningeal compartment, may point to a yet unknown function of mELT, which is independent of $B$ cells. Future studies are required, which aim to better understand the role and pathogenic relevance of $\mathrm{mELT}$ with and without B cells.

\section{Acknowledgment}

The authors would like to thank Melina Pekic Hajdarbasic, Beatrix Lunk, Olga Seelbach, Marion Mielke, Ulrike Mühlthaler (all TUM), and Vera Wolf and Sandra Meier (both Charité) for excellent technical assistance. The authors acknowledge support from F. Hoffmann-La Roche for providing the antimouse CD20 antibody 18B12. R.M. Brand is a fellow of the Hertie Foundation (medMS Doctoral Program).

\section{Study Funding}

This work was supported by the Deutsche Forschungsgemeinschaft (DFG, German Research Foundation) SFB TRR 130 TP17 to H. Radbruch. K. Lehmann-Horn received research support from the Deutsche Forschungsgemeinschaft (SFB-TR-128 and LE 3079/3-1), the Hertie Foundation (MyLab program), and the US National Multiple Sclerosis Society (NMSS) (G-1508-07064).

\section{Disclosure}

R.M. Brand, V. Friedrich, J. Diddens, M. Pfaller, F.R. de Franchis, H. Radbruch, and K. Steiger report no disclosures. B. Hemmer has served on scientific advisory boards for Novartis; he has served as DMSC member for AllergyCare, Polpharma, and TG therapeutics; he or his institution has received speaker honoraria from Desitin; his institution received research grants from Regeneron for MS research. He holds part of two patents: one for the detection of antibodies against KIR4.1 in a subpopulation of patients with MS and the other for genetic determinants of neutralizing antibodies to interferon. All conflicts are not relevant to the topic of this study. K. Lehmann-Horn has received research support (to TUM) from Novartis, honoraria, and compensation for travel expenses from Novartis, F. Hoffmann-La Roche, and Merck Serono. Go to Neurology.org/NN for full disclosures.

\section{Publication History}

Received by Neurology: Neuroimmunology \& Neuroinflammation January 25, 2021. Accepted in final form March 8, 2021. 
Appendix Authors

\begin{tabular}{|c|c|c|}
\hline Name & Location & Contribution \\
\hline $\begin{array}{l}\text { Rosa } \\
\text { Margareta } \\
\text { Brand }\end{array}$ & $\begin{array}{l}\text { Department of Neurology, } \\
\text { School of Medicine, } \\
\text { Technical University of } \\
\text { Munich, Germany }\end{array}$ & $\begin{array}{l}\text { Drafting/revision of the } \\
\text { article for content, including } \\
\text { medical writing for content; } \\
\text { major role in the acquisition } \\
\text { of data; study concept or } \\
\text { design; analysis or } \\
\text { interpretation of data }\end{array}$ \\
\hline
\end{tabular}

\begin{tabular}{lll}
\hline Verena & Department of Neurology, & Major role in the acquisition \\
Friedrich, & School of Medicine, & of data; analysis or \\
PhD & Technical University of & interpretation of data \\
& Munich, Germany & \\
\hline
\end{tabular}

\begin{tabular}{|c|c|c|}
\hline $\begin{array}{l}\text { Jolien } \\
\text { Diddens, MSc }\end{array}$ & $\begin{array}{l}\text { Department of Neurology, } \\
\text { School of Medicine, } \\
\text { Technical University of } \\
\text { Munich, Germany }\end{array}$ & $\begin{array}{l}\text { Drafting/revision of the } \\
\text { article for content, including } \\
\text { medical writing for content; } \\
\text { analysis or interpretation of } \\
\text { data }\end{array}$ \\
\hline
\end{tabular}

Monika Department of Neurology, Major role in the acquisition Pfaller, BSc School of Medicine, of data Technical University of Munich, Germany

\begin{tabular}{lll}
\hline $\begin{array}{l}\text { Francesca } \\
\text { Romana de } \\
\text { Franchis, MSc }\end{array}$ & $\begin{array}{l}\text { Department of Neurology, } \\
\text { School of Medicine, } \\
\text { Technical University of } \\
\text { Munich, Germany }\end{array}$ & $\begin{array}{l}\text { Major role in the acquisition } \\
\text { of data }\end{array}$ \\
\hline $\begin{array}{l}\text { Helena } \\
\text { Radbruch, } \\
\text { MD }\end{array}$ & $\begin{array}{l}\text { Department of } \\
\text { Neuropathology, Charite - } \\
\text { Universitätsmedizin Berlin, } \\
\text { Germany }\end{array}$ & $\begin{array}{l}\text { Drafting/revision of the } \\
\text { article for content, including } \\
\text { medical writing for content; } \\
\text { major role in the acquisition } \\
\text { of data; analysis or } \\
\text { interpretation of data }\end{array}$
\end{tabular}

\begin{tabular}{lll}
\hline Bernhard & Department of Neurology, & Drafting/revision of the \\
Hemmer, MD & $\begin{array}{l}\text { School of Medicine, } \\
\text { Technical University of }\end{array}$ & $\begin{array}{l}\text { article for content, including } \\
\text { medical writing for content }\end{array}$ \\
& Munich, Germany &
\end{tabular}
Munich, Germany

\begin{tabular}{lll}
\hline $\begin{array}{l}\text { Katja Steiger, } \\
\text { VMD }\end{array}$ & $\begin{array}{l}\text { Comparative Experimental } \\
\text { Pathology (CEP), } \\
\text { Department of Pathology, } \\
\text { School of Medicine, } \\
\text { Technical University of } \\
\text { Munich, Germany }\end{array}$ & $\begin{array}{l}\text { Drafting/revision of the } \\
\text { article for content, including } \\
\text { medical writing for content; } \\
\text { major role in the acquisition } \\
\text { of data; analysis or } \\
\text { interpretation of data }\end{array}$ \\
\hline $\begin{array}{l}\text { Klaus } \\
\text { Lehmann- } \\
\text { Horn, MD }\end{array}$ & $\begin{array}{l}\text { Department of Neurology, } \\
\text { School of Medicine, } \\
\text { Technical University of } \\
\text { Munich, Germany }\end{array}$ & $\begin{array}{l}\text { Drafting/revision of the article } \\
\text { for content, including medical } \\
\text { writing for content; study } \\
\text { concept or design; analysis or } \\
\text { interpretation of data }\end{array}$ \\
& &
\end{tabular}

\section{References}

1. Hauser SL, Waubant E, Arnold DL, et al. B-cell depletion with rituximab in relapsingremitting multiple sclerosis. N Engl J Med. 2008;358(7):676-688.

2. Hauser SL, Bar-Or A, Comi G, et al. Ocrelizumab versus interferon beta-1a in relapsing multiple sclerosis. $N$ Engl J Med. 2017;376(3):221-234.

3. Montalban X, Hauser SL, Kappos L, et al. Ocrelizumab versus placebo in primary progressive multiple sclerosis. N Engl J Med. 2017;376(3):209-220.

4. Ancau M, Berthele A, Hemmer B. CD20 monoclonal antibodies for the treatment of multiple sclerosis: up-to-date. Expert Opin Biol Ther. 2019;19(8):829-843.

5. Molnarfi N, Schulze-Topphoff U, Weber MS, et al. MHC class II-dependent B cell APC function is required for induction of CNS autoimmunity independent of myelinspecific antibodies. J Exp Med. 2013;210(13):2921-2937.

6. Sabatino JJ Jr, Probstel AK, Zamvil SS. B cells in autoimmune and neurodegenerative central nervous system diseases. Nat Rev Neurosci. 2019;20(12):728-745.
7. von Budingen HC, Palanichamy A, Lehmann-Horn K, Michel BA, Zamvil SS. Update on the autoimmune pathology of multiple sclerosis: B-cells as disease-drivers and therapeutic targets. Eur Neurol. 2015;73(3-4):238-246.

8. Weber MS, Hemmer B. Cooperation of B cells and T cells in the pathogenesis of multiple sclerosis. Results Probl Cell Differ. 2010;51:115-126.

9. Zamvil SS, Hauser SL. Antigen presentation by B cells in multiple sclerosis. N Engl J Med. 2021;384(4):378-381.

10. Serafini B, Rosicarelli B, Magliozzi R, Stigliano E, Aloisi F. Detection of ectopic B-cell follicles with germinal centers in the meninges of patients with secondary progressive multiple sclerosis. Brain Pathol. 2004;14(2):164-174.

11. Magliozzi R, Howell O, Vora A, et al. Meningeal B-cell follicles in secondary progressive multiple sclerosis associate with early onset of disease and severe cortical pathology. Brain. 2007;130(pt 4):1089-1104.

12. Howell OW, Reeves CA, Nicholas R, et al. Meningeal inflammation is widespread and linked to cortical pathology in multiple sclerosis. Brain. 2011;134(pt 9):2755-2771.

13. Lucchinetti CF, Popescu BF, Bunyan RF, et al. Inflammatory cortical demyelination in early multiple sclerosis. N Engl J Med. 2011;365:2188-2197.

14. Choi SR, Howell OW, Carassiti D, et al. Meningeal inflammation plays a role in the pathology of primary progressive multiple sclerosis. Brain. 2012;135(pt 10):2925-2937.

15. Reali C, Magliozzi R, Roncaroli F, Nicholas R, Howell OW, Reynolds R. B cell rich meningeal inflammation associates with increased spinal cord pathology in multiple sclerosis. Brain Pathol. 2020;30(4):779-793.

16. Pitzalis C, Jones GW, Bombardieri M, Jones SA. Ectopic lymphoid-like structures in infection, cancer and autoimmunity. Nat Rev Immunol. 2014;14:447-462.

17. Corsiero E, Nerviani A, Bombardieri M, Pitzalis C. Ectopic lymphoid structures: powerhouse of autoimmunity. Front Immunol. 2016;7:430.

18. Pikor NB, Prat A, Bar-Or A, Gommerman JL. Meningeal tertiary lymphoid tissues and multiple sclerosis: a gathering place for diverse types of immune cells during CNS autoimmunity. Front Immunol. 2015;6:657.

19. Jones GW, Jones SA. Ectopic lymphoid follicles: inducible centres for generating antigen-specific immune responses within tissues. Immunology. 2016;147(2):141-151.

20. Bell L, Lenhart A, Rosenwald A, Monoranu CM, Berberich-Siebelt F. Lymphoid aggregates in the CNS of progressive multiple sclerosis patients lack regulatory $\mathrm{T}$ cells. Front Immunol. 2019;10:3090.

21. Lehmann-Horn K, Wang SZ, Sagan SA, Zamvil SS, von Budingen HC. B cell repertoire expansion occurs in meningeal ectopic lymphoid tissue. JCI Insight. 2016; 1(20):e87234.

22. Lehmann-Horn K, Kinzel S, Feldmann L, et al. Intrathecal anti-CD20 efficiently depletes meningeal B cells in CNS autoimmunity. Ann Clin Transl Neurol. 2014;1(7): 490-496.

23. Krishnamoorthy G, Lassmann H, Wekerle H, Holz A. Spontaneous opticospinal encephalomyelitis in a double-transgenic mouse model of autoimmune $\mathrm{T}$ cell/B cell cooperation. J Clin Invest. 2006;116(9):2385-2392.

24. Bettelli E, Baeten D, Jager A, Sobel RA, Kuchroo VK. Myelin oligodendrocyte glycoprotein-specific T and B cells cooperate to induce a Devic-like disease in mice. J Clin Invest. 2006;116(9):2393-2402.

25. Dang AK, Tesfagiorgis Y, Jain RW, Craig HC, Kerfoot SM. Meningeal infiltration of the spinal cord by non-classically activated B cells is associated with chronic disease course in a spontaneous B cell-dependent model of CNS autoimmune disease. Front Immunol. 2015;6:470.

26. Kinzel S, Lehmann-Horn K, Torke S, et al. Myelin-reactive antibodies initiate T cellmediated CNS autoimmune disease by opsonization of endogenous antigen. Acta Neuropathol. 2016;132(1):43-58.

27. Varrin-Doyer M, Pekarek KL, Spencer CM, et al. Treatment of spontaneous EAE by laquinimod reduces Th, B cell aggregates, and disease progression. Neurol Neuroimmunol Neuroinflamm. 2016;3(5):e272.

28. Martin MdP, Cravens PD, Winger R, et al. Depletion of B Lymphocytes from cerebral perivascular spaces by rituximab. Arch Neurol. 2009;66(8):1016-1020.

29. esfandi S, Salimian S, Corboy J, Alvarez E. Persistent B lymphocytes in multiple sclerosis plaques after rituximab treatment (P5.341). Neurology. 2017;88(16 suppl):P5.341.

30. Parker Harp CR, Archambault AS, Cheung M, et al. Neutrophils promote VLA-4dependent $\mathrm{B}$ cell antigen presentation and accumulation within the meninges during neuroinflammation. Proc Natl Acad Sci USA. 2019;116(48):24221-24230.

31. Pipi E, Nayar S, Gardner DH, Colafrancesco S, Smith C, Barone F. Tertiary lymphoid structures: autoimmunity goes local. Front Immunol. 2018;9:1952.

32. Neyt K, Perros F, GeurtsvanKessel CH, Hammad H, Lambrecht BN. Tertiary lymphoid organs in infection and autoimmunity. Trends Immunol. 2012;33(6):297-305.

33. Jones GW, Hill DG, Jones SA. Understanding immune cells in tertiary lymphoid organ development: it is all starting to come together. Front Immunol. 2016;7:401.

34. Gago da Graca C, van Baarsen LGM, Mebius RE. Tertiary lymphoid structures: diversity in their development, composition, and role. J Immunol. 2021;206(2):273-281.

35. Carragher DM, Rangel-Moreno J, Randall TD. Ectopic lymphoid tissues and local immunity. Semin Immunol. 2008;20(1):26-42.

36. Weber MS, Prod'homme T, Patarroyo JC, et al. B-cell activation influences T-cell polarization and outcome of anti-CD20 B-cell depletion in central nervous system autoimmunity. Ann Neurol. 2010;68(3):369-383. 


\section{Neurology \\ Neuroimmunology \& Neuroinflammation}

\section{Anti-CD20 Depletes Meningeal B Cells but Does Not Halt the Formation of Meningeal Ectopic Lymphoid Tissue \\ Rosa Margareta Brand, Verena Friedrich, Jolien Diddens, et al. \\ Neurol Neuroimmunol Neuroinflamm 2021;8; \\ DOI 10.1212/NXI.0000000000001012}

This information is current as of May 21, 2021

\begin{abstract}
Updated Information \&
Services

References

Citations

Subspecialty Collections

Permissions \& Licensing

Reprints

including high resolution figures, can be found at:

http://nn.neurology.org/content/8/4/e1012.full.html

This article cites 36 articles, 4 of which you can access for free at: http://nn.neurology.org/content/8/4/e1012.full.html\#\#ref-list-1

This article has been cited by 2 HighWire-hosted articles: http://nn.neurology.org/content/8/4/e1012.full.html\#\#otherarticles

This article, along with others on similar topics, appears in the following collection(s):

Multiple sclerosis

http://nn.neurology.org//cgi/collection/multiple_sclerosis

Information about reproducing this article in parts (figures,tables) or in its entirety can be found online at:

http://nn.neurology.org/misc/about.xhtml\#permissions

Information about ordering reprints can be found online:

http://nn.neurology.org/misc/addir.xhtml\#reprintsus
\end{abstract}

Neurol Neuroimmunol Neuroinflamm is an official journal of the American Academy of Neurology.

Published since April 2014, it is an open-access, online-only, continuous publication journal. Copyright

Copyright (C) 2021 The Author(s). Published by Wolters Kluwer Health, Inc. on behalf of the American

Academy of Neurology.. All rights reserved. Online ISSN: 2332-7812.

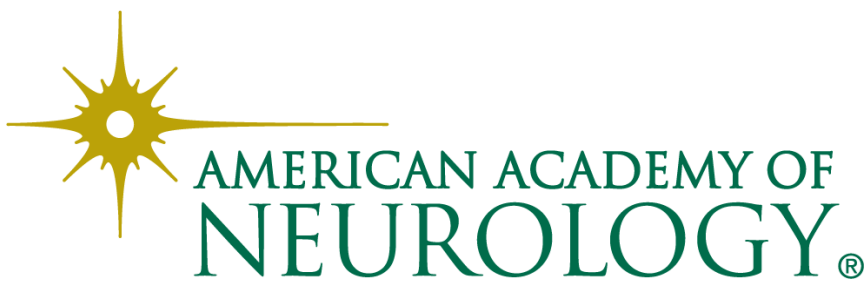

